\title{
Epstein-Barr virus in gastric carcinomas and gastric stump carcinomas: a late event in gastric carcinogenesis
}

\author{
A zur Hausen, B P van Rees, J van Beek, M E Craanen, E Bloemena, G J A Offerhaus, C J L M Meijer, \\ A J C van den Brule
}

See end of article for authors' affiliations

.....................

Correspondence to:

Dr E Bloemena

Department of Pathology,

Section Molecular

Pathology, Vrije

Universiteit Medical

Centre, PO Box 7057,

1007 MB Amsterdam, The

Netherlands;

e.bloemena@vumc.nl

Accepted for publication

10 December 2003
Background: To determine at what stage during gastric carcinogenesis Epstein-Barr virus (EBV) enters the gastric epithelial cells, the presence of EBV was investigated in two pathogenetically related but distinct forms of adenocarcinoma of the stomach-gastric carcinoma of the intact stomach (GCIS) and gastric stump carcinoma (GSC)- and their presumed precursor lesions.

Patients and methods: Eleven patients with EBV positive GCIS and eight patients with EBV positive GSC, demonstrated by the highly sensitive EBV encoded RNA 1/2 (EBER1/2) RNA in situ hybridisation (RISH) technique, were studied. Paraffin wax embedded tissue available from preoperative gastric biopsies and tumour adjacent tissue from the resection specimens containing normal gastric mucosa, inflamed gastric mucosa, and preneoplastic lesions (intestinal metaplasia and dysplasia) was investigated by EBER $1 / 2$ $\mathrm{RISH}$, in addition to EBV nuclear antigen 1 (EBNA-1) and latent membrane protein 1 (LMP-1) immunohistochemistry (IHC).

Results: In both GCIS and GSC and their precursor lesions EBER1/2 transcripts were restricted to the carcinoma cells. In addition, positivity of EBNA-1 IHC was also restricted to the tumour cells. IHC for LMP-1 was negative in all cases tested.

Conclusions: The absence of EBER1/2 transcripts in preneoplastic gastric lesions (intestinal metaplasia and dysplasia) and their presence in two distinct types of gastric carcinoma strongly suggest that EBV can only infect neoplastic gastric cells and thus is a late event in gastric carcinogenesis.
W orldwide, gastric carcinoma is one of the leading causes of cancer related mortality and clinical prognosis is very poor. ${ }^{1}$ The most commonly accepted hypothesis of gastric carcinogenesis of intestinal type carcinoma comprises a sequence of presumed precursor lesions: chronic atrophic gastritis (CAG) and intestinal metaplasia (IM). This has been shown to develop upon Helicobacter pylori infection, and is thought to lead to dysplasia and intestinal type gastric carcinoma. ${ }^{12}$ This is in contrast to the other major type of gastric carcinoma-diffuse type carcinoma-of which no precursor lesions have been identified to date.

During the past decade, accumulating evidence has indicated a role for the human pathogenic Epstein-Barr virus $(\mathrm{EBV})$ in gastric carcinogenesis. ${ }^{3-6} \mathrm{EBV}$ is found in approximately $10 \%$ of gastric adenocarcinomas not otherwise specified and it is estimated that worldwide each year 50 000-75 000 new cases of EBV carrying gastric carcinoma occur. ${ }^{5}$ In addition, $35 \%$ of gastric stump carcinomas (GSCs) are associated with EBV. ${ }^{7}$ GSCs are carcinomas that develop years after surgery for peptic ulcer disease, with an increased risk for men and Billroth II reconstruction. During the neoplastic process various precursor lesions of the intestinal type of gastric carcinoma are observed. ${ }^{89}$

"The knowledge of how and at what time point EpsteinBarr virus (EBV) enters the gastric epithelium would help to determine the role of EBV in gastric carcinogenesis"

However, the role of EBV in gastric carcinogenesis is not yet completely understood. We have recently shown that EBV carrying gastric carcinomas express the transforming BARFl gene of EBV and that EBV carrying gastric carcinomas are characterised by distinct chromosomal aberrations. ${ }^{10}{ }^{11}$ These data strongly argue for an important role for EBV in gastric carcinogenesis.

More than 30 years after the first report of EBV DNA in an epithelial malignancy (nasopharyngeal carcinoma), ${ }^{12}$ it remains unclear how EBV enters epithelial cells, because the EBV receptor CD21 is not expressed on epithelial cells. Similarly, it is not known how EBV enters the gastric epithelium or carcinoma cells. It has been reported that EBV is monoclonally present in all gastric carcinoma cells..$^{13}{ }^{14}$ The knowledge of how and at what time point EBV enters the gastric epithelium would help to determine the role of EBV in gastric carcinogenesis.

Previous reports concerning the detection of EBV in the presumed gastric carcinoma precursor lesions CAG, IM, and dysplasia are highly controversial. Some authors find EBV restricted to the carcinoma cells, ${ }^{13-15}$ whereas others report EBV in the precursor lesions and in the carcinoma cells. ${ }^{3}{ }^{16-18}$

In an attempt to determine the stage of gastric carcinogenesis at which EBV putatively enters the gastric epithelium we performed the highly sensitive EBV encoded RNA $1 / 2$ (EBERl/2) RNA in situ hybridisation technique (EBERl/2 RISH), which has been shown to be superior to EBV DNA in situ hybridisation. ${ }^{19}$ The material used included resection specimens of gastric carcinoma and gastric biopsies of patients after Billroth II resection and preoperative biopsies of patients with gastric carcinoma in the intact stomach (GCIS) comprising non-neoplastic, preneoplastic, and neoplastic gastric mucosa. EBERl/2 RISH was performed on all paraffin wax blocks that were available for each case,

Abbreviations: CAG, chronic atrophic gastritis; EBER, Epstein-Barr virus encoded RNA; EBNA, Epstein-Barr virus nuclear antigen; EBV, Epstein-Barr virus; GCIS, gastric carcinoma of the intact stomach; GSC, gastric stump carcinoma; IHC, immunohistochemistry; IM, intestinal metaplasia; LMP-1, latent membrane protein 1; RISH, RNA in situ hybridisation 
including normal gastric epithelium, CAG, IM, dysplasia, and carcinoma. In addition, we applied immunohistochemistry (IHC), for the EBV proteins-latent membrane protein 1 (LMP-1) and EBV nuclear antigen 1 (EBNA-1) - and the EBV receptor $(\mathrm{CD} 21)$.

\section{MATERIALS AND METHODS \\ Clinical materials \\ EBV carrying GCIS}

Samples from 11 EBV carrying GCIS patients were collected at the department of pathology, Vrije Universiteit medical centre Amsterdam, The Netherlands. These carcinomas were tested for the presence of EBV by EBERl/2 RISH, and data on 10 of these carcinomas have previously been described. ${ }^{10}$ All paraffin wax embedded material available from these casesthat is, all parts of the tumour and non-neoplastic tissue from the resection specimen and the preoperative biopsy ( $\mathrm{n}=7$ )-was submitted to EBERl/2 RISH. In total, 29 normal gastric epithelia, 10 with chronic atrophic gastritis, 18 with intestinal metaplasia, two low grades, and one moderate dysplasia were evaluated. The diagnoses were confirmed by an experienced gastrointestinal pathologist (GJAO). Table 1 summarises the clinicopathological data of these 11 gastric carcinomas. All tumours were adenocarcinomas not otherwise specified. No lymphoepithelial-like carcinomas were studied.

\section{EBV carrying GSC}

Samples from eight EBV carrying GSC patients, as determined by EBERI/2 RISH, were obtained from the department of pathology, Academic medical centre, University of Amsterdam, The Netherlands. Preceding biopsies $(\mathrm{n}=8)$, containing normal gastric epithelium, IM, dysplasia, and carcinoma, collected in the context of a longstanding follow up were also submitted to EBERI/2 RISH. In addition, gastric tissues from the resection specimens with IM and dysplasia adjacent to EBV positive gastric carcinomas were also submitted to EBERl/2 RISH. In total, 24 normal gastric epithelia, five with CAG, 14 with IM, and three low grade dysplasias were evaluated. The diagnoses were confirmed by an experienced gastrointestinal pathologist (GJAO). Table 2 summarises the clinicopathological data of the patients with GSC. No lymphoepithelial-like carcinomas were studied.

\section{EBER $1 / 2$ and $\beta$ actin RISH}

RISH was performed for the EBER $1 / 2$ transcripts and the $\beta$ actin target as described previously. ${ }^{20}$ Paraffin wax embedded tissues from preoperative biopsies and the gastrectomy of the tumour and adjacent non-neoplastic mucosa of EBV carrying GCIS and GSC samples were subjected to the non-radioactive EBERl/2 RISH using digoxygenin labelled antisense and sense EBERl/2 probes as described previously. ${ }^{20}$

Table 1 Summary of preoperative biopsy and resection data of patients with an EBV carrying gastric carcinoma of the intact stomach

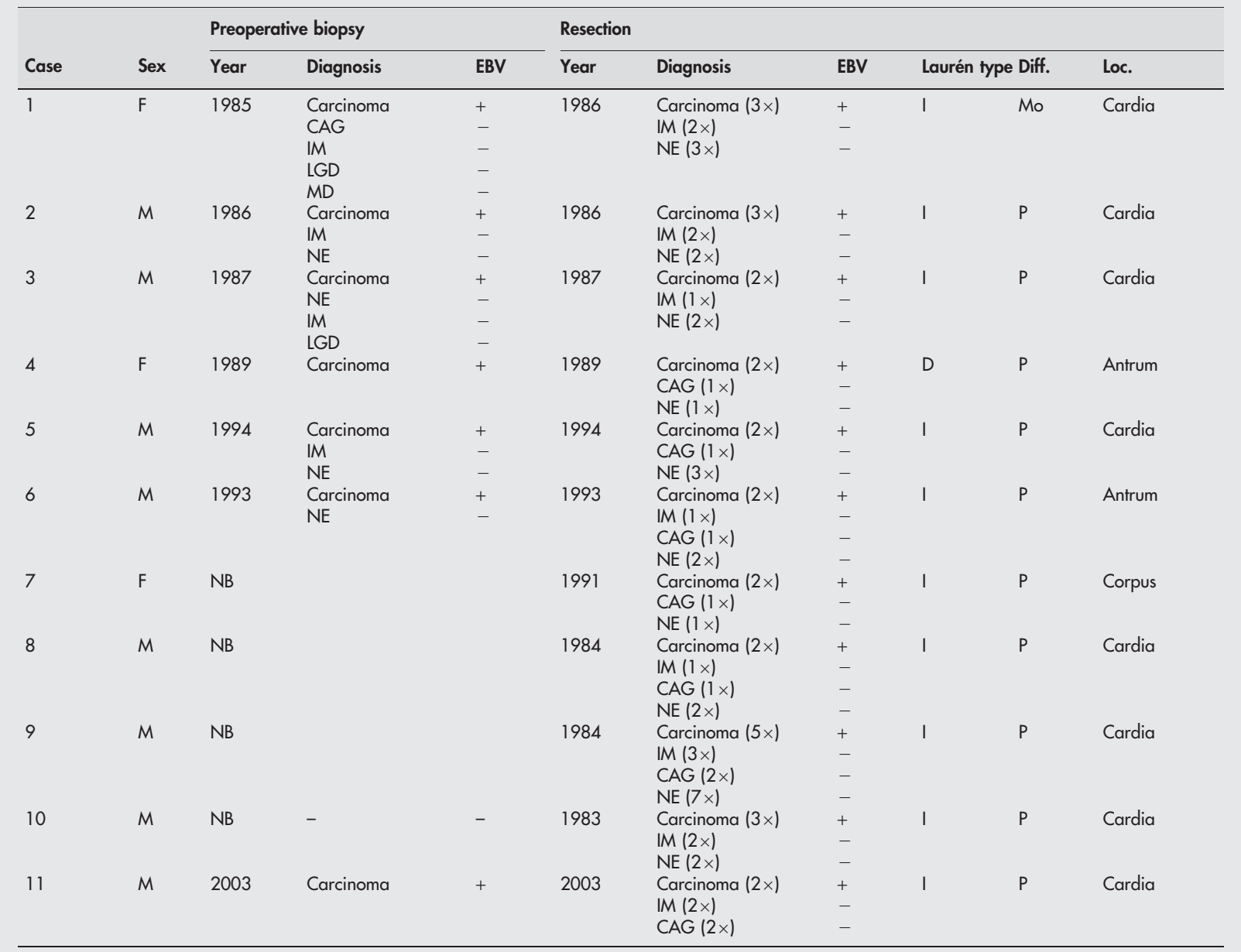

CAG, chronic atrophic gastritis; D, diffuse type; Diff., differentiation; EBV, Epstein-Barr virus; F, female; I, intestinal type; IM, intestinal metaplasia; Loc., localisation; LGD, low grade dysplasia; $M$, male; MD, moderate dysplasia; NB, no biopsy available; NE, normal epithelium; $P$, poorly.

The presence of EBV was tested by EBV encoded RNA in situ hybridisation; the numbers in parenthesis indicate the frequency of the lesion tested for EBV. 


\section{Immunohistochemistry}

To detect EBV specific proteins, which are known to be expressed in EBV associated epithelial malignancies, ${ }^{19}$ monoclonal antibodies against LMP-1 (CSI-4; Dako, Glostrup, Denmark) and EBNA-1 (2B4-1; a kind gift from Dr Grässer, Homburg, Germany) were used. Detection of the EBV receptor was performed with a monoclonal anti-CD21 antibody (Dako; clone 1F8). All antibodies were visualised with an avidin-biotin-horseradish peroxidase complex and diaminobenzidine $/ \mathrm{H}_{2} \mathrm{O}_{2}$ staining method, as described previously by our laboratory. ${ }^{20-22}$

\section{RESULTS}

\section{EBV carrying GCIS}

EBERl/2 positivity was found in all tumour cells of the 11 EBV carrying GCISs, both in the resection specimens and in the preoperative biopsies (table 1; fig 1A). ${ }^{10}$ EBERl/2 transcripts were never found in the mucosa adjacent to these EBV carrying GCISs, comprising normal gastric tissue $(\mathrm{n}=29)$, CAG $(\mathrm{n}=10)$, IM $(\mathrm{n}=18)$, and dysplasia $(\mathrm{n}=3)$ (table 1$)$. RISH for $\beta$ actin performed on corresponding tissue sections revealed sufficient RNA quality. IHC for EBNA-1 and LMP-1 expression on representative tissue of 10 of the cases showed the presence of EBNA-1 protein in the carcinoma cells in four of 10 cases (fig 1B), ${ }^{10}$ whereas no LMP-1 staining was found in the neoplastic cells or nonneoplastic epithelial cells (fig lC). EBNA-1 expression was not detected in the adjacent gastric mucosa of the four EBNA-1 positive gastric carcinomas, neither in the normal epithelium $(n=13)$ nor in areas of IM $(n=3)$.

Moreover, CD21 IHC was performed on EBV carrying GCIS and its precursor lesions. No positive staining was found in non-neoplastic or neoplastic epithelial cells (fig l D), whereas positive staining was seen in dendritic cells and B cells.

\section{Gastric stump carcinomas}

Specific nuclear EBERl/2 RISH transcripts were restricted to the tumour cells of GSCs in the gastrectomy specimens and the preceding biopsies $(\mathrm{n}=17$ ) (table 2, fig 2 ). No EBERl/2 transcripts were detected in normal gastric epithelium $(\mathrm{n}=24)$, CAG $(\mathrm{n}=5)$, or IM $(\mathrm{n}=14)$ in the mucosa adjacent to the carcinoma tissue of both the gastrectomy tissue (fig 2A and B) and the preoperative biopsies (table 2). In three cases (patients 6, 7, and 8), biopsy material was available 4,18 , and 18 years before the diagnosis gastric carcinoma, respectively. These biopsies all contained low grade dysplasia. In all of these cases, EBERl/2 RISH was negative in the preceding biopsy, both in the normal and the dysplastic epithelium (table 2)

The resection cases were tested for LMP-1 expression by immunohistochemistry $(\mathrm{n}=8)$. No positive staining for LMP-1 was detected in the carcinoma cells, the preneoplastic lesions, or non-neoplastic gastric epithelium.

\section{DISCUSSION}

Growing evidence of a role for EBV in gastric carcinogenesis derives from the following observations: EBV carrying gastric carcinomas harbour distinct chromosomal aberrations and are characterised by a unique transcription pattern resembling but not identical to nasopharyngeal carcinomas. ${ }^{10}{ }^{11}$ In addition, EBV carrying gastric carcinomas display specific clinical features compared with EBV negative gastric carcinomas. ${ }^{22 a}$ Therefore, the purpose of our present study was to determine the stage of gastric carcinogenesis at which EBV possibly enters the gastric epithelium. Although not firmly established, the present hypothesis on gastric carcinogenesis-of at least the intestinal type of gastric carcinomacomprises the sequence of gastritis, CAG, IM, dysplasia, and invasive carcinoma. ${ }^{2}$ Therefore, we investigated the presence of EBERl/2 transcripts in these presumed precursor lesions

Table 2 Summary of preoperative biopsy and resection data of patients with EBV carrying gastric stump carcinoma

\begin{tabular}{|c|c|c|c|c|c|c|c|c|c|}
\hline \multirow[b]{2}{*}{ Case } & \multirow[b]{2}{*}{ Sex } & \multicolumn{3}{|c|}{ Preoperative biopsy } & \multicolumn{5}{|c|}{ Carcinoma resection } \\
\hline & & Year & Diagnosis & EBV & $\begin{array}{l}\text { Carcinoma } \\
\text { surgery }\end{array}$ & Diagnosis & EBV & $\begin{array}{l}\text { Laurén } \\
\text { type }\end{array}$ & PU surgery \\
\hline 1 & M & 1981 & Carcinoma & + & 1982 & $\begin{array}{l}\text { Carcinoma }(2 \times) \\
\text { IM }(3 \times) \\
\text { NE }(3 \times)\end{array}$ & $\begin{array}{l}+ \\
+ \\
-\end{array}$ & 1 & 1946 \\
\hline 2 & M & 1979 & $\begin{array}{l}\text { Carcinoma } \\
\text { NE }\end{array}$ & $\begin{array}{l}+ \\
-\end{array}$ & 1979 & $\begin{array}{l}\text { Carcinoma }(2 \times) \\
\operatorname{IM}(4 \times) \\
\text { LGD }(1 \times) \\
\text { NE }(4 \times)\end{array}$ & $\begin{array}{l}+ \\
- \\
- \\
-\end{array}$ & I & 1957 \\
\hline 3 & $M$ & 1977 & $\begin{array}{l}\text { Carcinoma } \\
\text { CAG } \\
\text { NE }\end{array}$ & $\begin{array}{l}+ \\
- \\
-\end{array}$ & 1980 & $\begin{array}{l}\text { Carcinoma }(1 \times) \\
\text { IM }(1 \times) \\
\text { NE }(1 \times)\end{array}$ & $\begin{array}{l}+ \\
- \\
-\end{array}$ & I & 1954 \\
\hline 4 & M & 1979 & $\begin{array}{l}\text { Carcinoma } \\
\text { NE }\end{array}$ & $\begin{array}{l}+ \\
-\end{array}$ & 1980 & $\begin{array}{l}\text { Carcinoma }(2 \times) \\
\text { IM }(1 \times) \\
\text { CAG }(1 \times) \\
\text { NE }(2 \times)\end{array}$ & $\begin{array}{l}+ \\
- \\
- \\
-\end{array}$ & 1 & 1954 \\
\hline 5 & $M$ & 1978 & Carcinoma & + & 1979 & $\begin{array}{l}\text { Carcinoma }(1 \times) \\
\operatorname{IM}(2 \times) \\
\text { CAG }(1 \times) \\
\text { NE }(3 \times)\end{array}$ & $\begin{array}{l}+ \\
- \\
- \\
-\end{array}$ & 1 & 1951 \\
\hline 6 & $M$ & 1976 & $\begin{array}{l}\text { LGD } \\
\text { NE }\end{array}$ & $\begin{array}{l}- \\
-\end{array}$ & 1980 & $\begin{array}{l}\text { Carcinoma }(2 \times) \\
\text { CAG }(2 \times) \\
\text { NE }(2 \times)\end{array}$ & $\begin{array}{l}+ \\
- \\
-\end{array}$ & I & 1942 \\
\hline 7 & M & 1978 & $\begin{array}{l}\text { LGD } \\
\text { NE }\end{array}$ & $\begin{array}{l}- \\
-\end{array}$ & 1996 & $\begin{array}{l}\text { Carcinoma }(1 \times) \\
\text { IM }(1 \times) \\
\text { NE }(1 \times)\end{array}$ & $\begin{array}{l}+ \\
- \\
-\end{array}$ & I & 1955 \\
\hline 8 & M & 1976 & $\begin{array}{l}\text { LGD } \\
\text { NE }\end{array}$ & - & 1994 & $\begin{array}{l}\text { Carcinoma }(1 \times) \\
\text { IM }(2 \times) \\
\text { NE }(2 \times)\end{array}$ & $\begin{array}{l}+ \\
- \\
-\end{array}$ & I & 1944 \\
\hline
\end{tabular}

$C A G$, chronic atrophic gastritis; $E B V$, Epstein-Barr virus; $F$, female; IM, intestinal metaplasia; $L G D$, low grade dysplasia; $M$, male; $M D$, moderate dysplasia; $N E$, normal epithelium; PU, peptic ulcer.

The presence of EBV was tested by EBV encoded RNA in situ hybridisation; the numbers in parenthesis indicate the frequency of the lesion tested for EBV. 

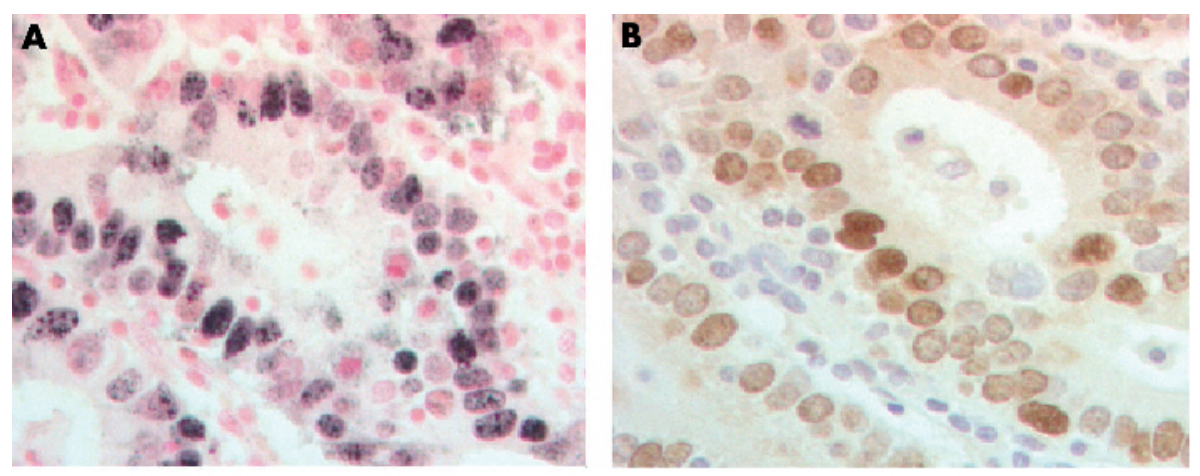

Figure 1 (A) Epstein-Barr virus (EBV) encoded RNA $1 / 2$ (EBER1/2) RNA in situ hybridisation in a gastric carcinoma of the intact stomach revealing specific EBER1/2 transcripts (dark) in the nuclei of the tumour cells. A corresponding slide shows (B) tumour cells with specific nuclear expression of EBV nuclear antigen 1 (dark brown), whereas (C) staining for latent membrane protein 1 is negative. (D) Expression of CD21 (brown) is restricted to dendritic cells, whereas the overlying gastric epithelium is negative.
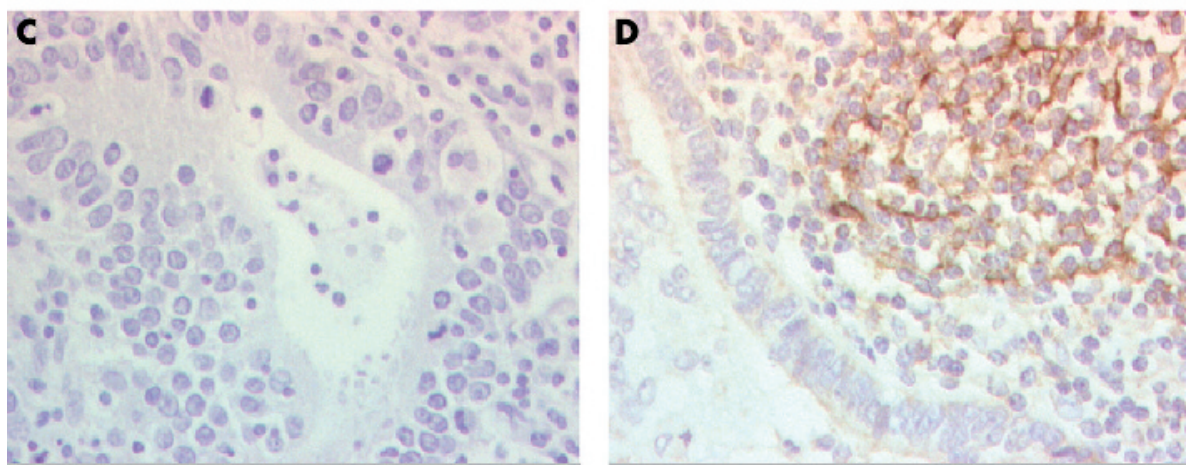

and neoplastic gastric epithelium of EBV carrying GCIS and GSC samples. Because the viral genome is present in limited numbers in most EBV associated malignancies, DNA ISH is not very sensitive. Therefore, we used EBER RISH, a technique that measures EBERl/2 RNAs, which are highly abundant in most EBV carrying tumour cells, and is the most sensitive method to demonstrate the presence of EBV. ${ }^{19}$ This is the first study in which two types of gastric carcinoma (GCIS and GCS) were investigated and all available paraffin embedded material from each case was analysed.

Specific nuclear EBERI/2 transcripts were found only in the carcinoma cells of both types of gastric carcinoma, and not in the adjacent normal, metaplastic, or dysplastic epithelia. In addition, EBV was detected in none of the normal or dysplastic epithelia of the preceding biopsies in EBV positive GSC.

In addition to EBERl/2 RISH, IHC for EBNA-1 and LMP-1 was carried out. Expression of EBNA-1 was restricted to gastric carcinoma cells (GCIS). No expression was found in the presumed precursor lesions of gastric carcinoma. EBNA-1 protein expression as measured by IHC was not detected in the cases of EBV positive gastric carcinoma probably because of the low content of EBNA-1 and the lower sensitivity of IHC in comparison with EBERl/2 RISH. ${ }^{22}$ Interestingly, LMP-1 expression was not found in the EBV positive carcinomas and their precursor lesions, which is in line with previous observations. ${ }^{23} 24$

\section{"Our data strongly suggest that Epstein-Barr virus is only present in susceptible cells of gastric carcinomas but not in its supposed precursor lesions"}

Our results agree with other studies in which EBER transcripts have not been detected in adjacent precursor lesions, such as IM. ${ }^{13-15}{ }^{23}$ However, some reports describe the presence of EBV in dysplasia, ${ }^{316}$ and some even in IM and CAG. ${ }^{17}{ }^{18}$ There are several reasons for these discrepancies. First, the problem associated with diagnosing dysplasia and carcinoma is well recognised..$^{2}$ In addition, dysplasias adjacent to carcinomas are difficult to distinguish from local carcinoma spread. The second reason is the use of different techniques and the interpretation of the results. Yanai and co-workers reported EBNA-1 and LMP-1 staining in CAG and IM. ${ }^{17}$ Because we used the same antibodies for EBNA- 1 and LMP-1 this discrepancy is surprising. However, in our longstanding experience with these antibodies, ${ }^{10} 2122$ we have found that crossreactivity can occur and that the interpretation of positive IHC results should always be done in the context of transcript analysis by reverse transcription polymerase chain reaction. ${ }^{10} 22$

It is of interest that EBV carrying GCIS and EBV carrying GSC did not differ with respect to the distribution of EBERI/2 transcripts. Although the carcinogenesis of both of these entities is closely linked to $H$ pylori, in GSC bile reflux is thought to play a major role in the multistep process of gastric carcinogenesis.

The fact that the expression of EBERl/2 transcripts and EBNA-1 protein is restricted to the tumour cells in EBV carrying GCIS and GSC strongly indicates that EBV enters the gastric epithelium at a late stage of the multistep process of gastric carcinogenesis. In addition, we showed that CD21, the EBV receptor, is not present in normal, preneoplastic, and neoplastic gastric cells. This is in line with the observations of others, ${ }^{25-27}$ and suggests the existence of an alternative EBV receptor on epithelial cells, ${ }^{28}{ }^{29}$ or an alternative route of entry of EBV into epithelial cells.

Because dysplasias are EBERl/2 RISH negative and all tumour cells carry EBV it is highly likely that EBV infects a neoplastic gastric epithelial cell, providing a growth advantage to the EBV positive tumour cell. Alternatively, EBV might infect a highly dysplastic gastric epithelial cell, transforming it into a carcinoma cell. Another explanation might be that gastric carcinogenesis develops through an as yet unknown route, in which the morphology of the precursor lesion has not yet been identified. However, all hypotheses point to a role for EBV late in the process of gastric carcinogenesis and explain why monoclonal EBV has been reported in all tumour cells of EBV carrying GCISs and GSCs. 

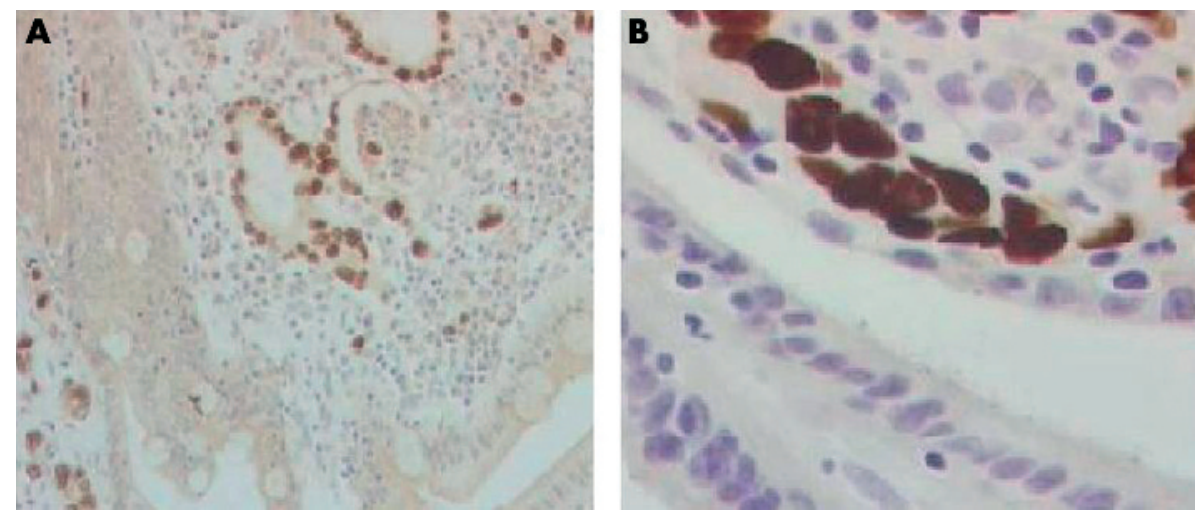

Figure 2 (A) Epstein-Barr virus (EBV) encoded RNA 1/2 (EBER1/2) positive tumour cells (dark brown) of a gastric stump carcinoma (GSC) adjacent to EBER 1/2 negative gastric epithelium with intestinal metaplasia. (B) EBER1/2 positive tumour cells (dark brown) of a GSC adjacent to EBER $1 / 2$ negative overlying gastric epithelium

\section{Take home messages}

- Epstein-Barr virus (EBV) encoded RNA $1 / 2$ (EBER1/2) transcripts were found in gastric carcinoma of the intact stomach (GCIS) and gastric stump carcinoma (GSC) but not in preneoplastic gastric lesions (intestinal metaplasia and dysplasia)

- This suggests that EBV can only infect neoplastic gastric cells and thus is a late event in gastric carcinogenesis

In summary, our data strongly suggest that EBV is only present in susceptible cells of gastric carcinomas but not in its supposed precursor lesions. This suggests that EBV enters the gastric epithelium at a late stage of the multistep carcinogenic process and that EBV plays a role late in the process of gastric carcinogenesis. This is strengthened by the demonstration of restricted EBV transcription in the tumour cells of two pathogenetically related but distinct models of gastric carcinogenesis.

\section{Authors' affiliations}

A zur Hausen, J van Beek, E Bloemena, C J L M Meijer, A J C van den Brule, Department of Pathology, Section Molecular Pathology, Vrije Universiteit Medical Centre, PO Box 7057, 1007 MB Amsterdam, The Netherlands

M E Craanen, Department of Gastroenterology, Vrije Universiteit Medical Centre

B P van Rees, G J A Offerhaus, Department of Pathology, Academic Medical Centre, 1100 DD Amsterdam, The Netherlands

The first two authors contributed equally to this work.

\section{REFERENCES}

1 World Health Organisation. Classification of tumours. Pathology and genetics, tumours of the digestive system. Lyon: IARC, 2000.

2 Schlemper RJ, Kato Y, Stolte M. Review of histological classifications of gastrointestinal epithelial neoplasia: differences in diagnosis of early carcinomas between Japanese and Western pathologists. J Gastroenterol 2001;36:445-56

3 Shibata D, Weiss LM. Epstein-Barr virus-associated gastric adenocarcinoma. Am J Pathol 1992;140:769-74.

4 Takano Y, Kato Y, Saegusa M, et al. The role of the Epstein-Barr virus in the oncogenesis of $\mathrm{EBV}(+)$ gastric carcinomas. Virchows Arch 1999;434:17-22.

5 Takada K. Epstein-Barr virus and gastric carcinoma. Mol Pathol 2000;53:255-61.

6 Herrmann K, Niedobitek G. Epstein-Barr virus-associated carcinomas: facts and fiction. J Pathol 2003;199:140-5.

7 Baas IO, van Rees BP, Musler A, et al. Helicobacter pylori and Epstein-Barr virus infection and the $\mathrm{p} 53$ tumour suppressor pathway in gastric stump cancer compared with carcinoma in the non-operated stomach. J Clin Pathol 1998;51:662-6.

8 Offerhaus GJ, van de Stadt J, Huibregtse K, et al. The mucosa of the gastric remnant harboring malignancy. Histologic findings in the biopsy specimens of 504 asymptomatic patients 15 to 46 years after partial gastrectomy with emphasis on nonmalignant lesions. Cancer 1989;64:698-703.

9 Offerhaus GJ. Gastric stump cancer: lessons from old specimens. Lancet 1994;343:66-7.

10 zur Hausen A, Brink AA, Craanen ME, et al. Unique transcription pattern of Epstein-Barr virus (EBV) in EBV-carrying gastric adenocarcinomas: expression of the transforming BARF1 gene. Cancer Res 2000;60:2745-8.

11 zur Hausen A, van Grieken NC, Meijer GA, et al. Distinct chromosomal aberrations in Epstein-Barr virus-carrying gastric carcinomas tested by comparative genomic hybridization. Gastroenterology 2001;121:612-18.

12 zur Hausen H, Schulte-Holthausen H, Klein G, et al. EBV DNA in biopsies of Burkitt tumours and anaplastic carcinomas of the nasopharynx. Nature 1970;228:1056-8.

13 Ott G, Kirchner T, Muller-Hermelink HK. Monoclonal Epstein-Barr virus genomes but lack of EBV-related protein expression in different types of gastric carcinoma. Histopathology 1994;25:323-9.

14 Imai S, Koizumi S, Sugiura M, et al. Gastric carcinoma: monoclonal epithelial malignant cells expressing Epstein-Barr virus latent infection protein. Proc Natl Acad Sci U S A 1994;91:9131-5.

15 Yamamoto N, Tokunaga M, Uemura $Y$, et al. Epstein-Barr virus and gastric remnant cancer. Cancer 1994;74:805-9.

16 Gulley ML, Pulitzer DR, Eagan PA, et al. Epstein-Barr virus infection is an early event in gastric carcinogenesis and is independent of bcl-2 expression and p53 accumulation. Hum Pathol 1996;27:20-7.

17 Yanai H, Takada K, Shimizu N, et al. Epstein-Barr virus infection in noncarcinomatous gastric epithelium. J Pathol 1997;183:293-8.

18 Yanai H, Murakami T, Yoshiyama H, et al. Epstein-Barr virus-associated gastric carcinoma and atrophic gastritis. J Clin Gastroenterol 1999;29:39-43.

19 Middeldorp JM, Brink AA, van den Brule AJ, et al. Pathogenic roles for Epstein-Barr virus (EBV) gene products in EBV-associated proliferative disorders. Crit Rev Oncol Hematol 2003;45:1-36.

20 Jiwa NM, Kanavaros P, van der Valk P, et al. Expression of c-myc and bcl-2 oncogene products in Reed-Sternberg cells independent of presence of Epstein-Barr virus. J Clin Pathol 1993:46:211-17.

21 Jiwa NM, Oudejans JJ, Dukers DF, et al. Immunohistochemical demonstration of different latent membrane protein-1 epitopes of Epstein-Barr virus in lymphoproliferative diseases. J Clin Pathol 1995;48:438-42.

22 Cruz I, Van Den Brule AJ, Brink AA, et al. No direct role for Epstein-Barr virus in oral carcinogenesis: a study at the DNA, RNA and protein levels. Int J Cancer 2000;86:356-61.

22 van Beek J, zur Hausen A, Klein Kranenbarg E, et al. EBV-positive gastric adenocarcinomas: a distinct clinicopathological entity with a low frequency of lymph node involvement. J Clin Oncol 2004;22:664-70.

23 Selves J, Bibeau $F$, Brousset $P$, et al. Epstein-Barr virus latent and replicative gene expression in gastric carcinoma. Histopathology 1996;28:121-7.

24 Hoshikawa Y, Satoh Y, Murakami M, et al. Evidence of lytic infection of Epstein-Barr virus (EBV) in EBV-positive gastric carcinoma. J Med Virol 2002;66:351-9.

25 Kim YS, Paik SR, Kim HK, et al. Epstein-Barr virus and CD21 expression in gastrointestinal tumors. Pathol Res Pract 1998;194:705-11.

26 Harn HJ, Chang JY, Wang MW, et al. Epstein-Barr virus-associated gastric adenocarcinoma in Taiwan. Hum Pathol 1995;26:267-71.

27 Shin WS, Kang MW, Kang JH, et al. Epstein-Barr virus-associated gastric adenocarcinomas among Koreans. Am J Clin Pathol 1996;105:174-81.

28 Yoshiyama H, Imai S, Shimizu N, et al. Epstein-Barr virus infection of human gastric carcinoma cells: implication of the existence of a new virus receptor different from CD21. J Virol 1997;71:5688-91.

29 Takasaka N, Tajima M, Okinaga K, et al. Productive infection of Epstein-Barr virus (EBV) in EBV-genome-positive epithelial cell lines (GT38 and GT39) derived from gastric tissues. Virology 1998;247:152-9. 